\title{
Morphological differences during in vitro chondrogenesis of bone marrow-, synovium-MSCs, and chondrocytes
}

\author{
Shizuko Ichinose ${ }^{1,6}$, Takeshi Muneta ${ }^{2,3}$, Hideyuki Koga ${ }^{2}$, Yuko Segawa ${ }^{2}$, Motoki Tagami ${ }^{4}$, Kunikazu Tsuji ${ }^{3}$ and \\ Ichiro Sekiya ${ }^{5,6}$
}

Mesenchymal stem cells (MSCs) from a variety of mesenchymal tissue contain common features, but distinguishing properties dependent on their origin are emerging. We investigated morphological differences of human bone marrowMSCs, synovium-MSCs, and chondrocytes during in vitro chondrogenesis. Two hundred thousands cells were pelleted after centrifugation and cultured in chondrogenic media that contained BMP-2, TGF- $\beta 3$, and dexamethasone. The pellets were analyzed histologically, immunohistologically, and electron microscopically. Before chondrogenic induction, trypsinized MSCs and chondrocytes looked similar. At day 1, the structure of the three masses was divided into two layers, and the most obvious differences in the three populations were observed in the deep zone. In bone marrow-MSCs, round cells accumulated without intercellular space, and the cells were mainly connected through intermediate junctions. In synovium-MSCs, elongated cells accumulated with small desmosomes and intercellular spaces could occasionally be seen. In chondrocytes, separated oval and polygonal cells connected only in a narrow spotty area through a small desmosome. At day 7, the structure of the three masses was divided into three layers, and the most obvious differences in the three populations were observed in the middle zone. In bone marrow-MSCs, the middle zone consisted of dense smaller cells and apoptotic cells. In synovium-MSCs, the middle zone consisted of dense arrayed wider cells and apoptotic cells. In chondrocytes, the middle zone was acellular without apoptotic cells. At day 21, the morphology of cells and extracellular space became similar in that each cell was located separately with abundant extracellular matrix. The superficial zone was still obvious in bone marrow-MSCs, but hardly seen both in synovium-MSCs and chondrocytes. In this study, we revealed morphological differences of bone marrow-MSCs, synovium-MSCs, and chondrocytes during in vitro chondrogenesis. The most obvious differences in the three populations were observed at day 1 in the deep zone. Laboratory Investigation (2010) 90, 210-221; doi:10.1038/labinvest.2009.125; published online 14 December 2009

KEYWORDS: mesenchymal stem cells; chondrogenesis; bone marrow; synovium; chondrocytes

Toward the development of cell therapy for cartilage regeneration, mesenchymal stem cells (MSCs) are attractive because of their chondrogenic potential. ${ }^{1-4}$ MSCs can be obtained from a variety of mesenchymal tissues including bone marrow, ${ }^{5}$ which seems to be the most popular MSC source at present. Synovium, a thin membrane covering the inside of joints, is another promising MSC source due to its high chondrogenic potential. ${ }^{6-8}$ MSCs derived from various mesenchymal tissues contain common features, but distinguishing properties due to their origin are emerging. ${ }^{9-12}$ However, morphological differences of MSCs dependent on the source, especially during chondrogenesis, remain unknown.

Chondrocyte transplantation is currently one of the prevailing methods for cartilage regeneration therapy. ${ }^{13}$ The digested and expanded chondrocytes produce cartilage

\footnotetext{
${ }^{1}$ Instrumental Analysis Research Center, Tokyo Medical and Dental University, Tokyo, Japan; ${ }^{2}$ Section of Orthopaedic Surgery, Graduate School, Tokyo Medical and Dental University, Tokyo, Japan; ${ }^{3}$ Global Center of Excellence Program, International Research Center for Molecular Science in Tooth and Bone Diseases, Tokyo Medical and Dental University, Tokyo, Japan; ${ }^{4}$ Department of Medicine, Sanraku Hospital, Tokyo, Japan and ${ }^{5}$ Section of Cartilage Regeneration, Graduate School, Tokyo Medical and Dental University, Tokyo, Japan

Correspondence: Dr I Sekiya, MD, PhD, Section of Cartilage Regeneration, Graduate School, Tokyo Medical and Dental University, 1-5-45 Yushima, Bunkyo-ku, Tokyo 113-8519, Japan.

E-mail: sekiya.orj@tmd.ac.jp

${ }^{6}$ These authors contributed equally to this work.

Received 21 May 2009; revised 21 September 2009; accepted 24 September 2009
} 
matrix again when cultured in a proper condition. This process seems to contain some similarities to that in MSCs, and it would be intriguing to compare the morphology of MSCs and chondrocytes during their chondrogenesis.

Ectopic cartilage formations such as chondrophyte, free body, and metaplasia are one of the pathological conditions in articular joints. ${ }^{14}$ Cell sources and the pathophysiology of ectopic cartilage formations are poorly understood. We speculate that cell sources for the ectopic cartilage formations are stem cells in bone marrow and synovium, in addition to chondrocytes.

In this study, we compared the morphology of bone marrow-, synovium-MSCs, and chondrocytes during in vitro chondrogenesis. Our results shed light on some aspects of both the mesenchymal stem biology and pathophysiology of ectopic cartilage formations.

\section{MATERIALS AND METHODS Isolation of Bone Marrow-, Synovium-MSCs, and Chondrocytes}

The study was approved by an institutional review board, and informed consent was obtained from all study subjects. Human bone marrow, synovium, and cartilage were harvested from three patients during total knee arthroplasty with medial compartment osteoarthritis. The patients were all females, 68,70 , and 73 years old. Bone marrow was aspirated from the tibia with an 18-gauge needle during the operation. Synovial tissue was harvested from the suprapatellar pouch. Cartilage was obtained from resected lateral femoral condyle. Nucleated cells from bone marrow were isolated with Ficoll density gradient (Ficoll-Paque, Pharmacia Biosystems, Uppsala, Sweden). Synovium and cartilage were minced into small pieces, digested in a collagenase solution, and filtered. Nucleated cells from synovium and cartilage were plated at $10^{3}, 10^{4}$, or $10^{5}$ cells $/ 60-\mathrm{cm}^{2}$ dish (Nalge Nunc International, Rochester, NY, USA), and those from bone marrow at $10^{4}, 10^{5}$, or $10^{6}$ cells $/ 60-\mathrm{cm}^{2}$ dish. The cells were plated in six dishes and cultured in $10 \mathrm{ml}$ complete culture medium: $\alpha \mathrm{MEM}$ containing $10 \%$ fetal bovine serum (Invitrogen, Carlsbad, CA, USA), 100 units $/ \mathrm{ml}$ penicillin (Invitrogen), $100 \mathrm{mg} / \mathrm{ml}$ streptomycin (Invitrogen), and $250 \mathrm{ng} / \mathrm{ml}$ amphotericin B (Invitrogen) for 14 days as passage 0 . Three dishes for each cell concentration were stained with $0.5 \%$ crystal violet. The optimal initial cell density was determined based on the following criteria: (1) the colony size was not affected by contact inhibition, and (2) the greatest number of colonies was obtained. We then harvested the cells plated at optimal densities from the three remaining dishes. Passage 0 cells were replated at 50 cells $/ \mathrm{cm}^{2}$ in a $145-\mathrm{cm}^{2}$ dish and cultured for 14 days for the analyses. ${ }^{11}$

\section{Surface Epitopes}

One million cells were suspended in $200 \mathrm{ml}$ PBS containing $20 \mathrm{mg} / \mathrm{ml}$ of antibody, incubated for $30 \mathrm{~min}$ at $48^{\circ} \mathrm{C}$, and resuspended in $1 \mathrm{ml}$ of PBS. Fluorescein isothiocyanate (FITC)- or phycoerythrin (PE)-coupled antibodies against CD90 and CD45 were from Becton Dickinson; CD44 was from eBioscience (San Diego, CA, USA); and CD105 was from Ancell Corporation (Bayport, MN, USA). For the isotype control, FITC- or PE-coupled nonspecific mouse IgG (Becton Dickinson) was substituted for the primary antibody. Cell fluorescence was evaluated by FACSCalibur instrument (Becton Dickinson), and data were analyzed using CellQuest software (Becton Dickinson). ${ }^{11,15}$

\section{Chondrogenesis}

Two hundred thousands cells at passage 2 were placed in a 15-ml polypropylene tube (Becton Dickinson) and centrifuged at $450 \mathrm{~g}$ for $10 \mathrm{~min}$. The pellets were cultured at $37^{\circ} \mathrm{C}$ with $5 \% \mathrm{CO}_{2}$ in $400 \mu \mathrm{l}$ chondrogenic media that contained $500 \mathrm{ng} / \mathrm{ml}$ bone morphogenetic protein 2 (Astellas Pharm, Tokyo, Japan), $10 \mathrm{ng} / \mathrm{ml}$ transforming growth factor- $\beta 3$ (R\&D Systems, Minneapolis, MN, USA), $100 \mathrm{nM}$ dexamethasone, $50 \mu \mathrm{g} / \mathrm{ml}$ ascorbate-2-phosphate, $\quad 40 \mu \mathrm{g} / \mathrm{ml}$ proline, $100 \mu \mathrm{g} / \mathrm{ml}$ pyruvate (Sigma-Aldrich), and $50 \mathrm{mg} / \mathrm{ml}$ ITS + Premix in high-glucose Dulbecco modified Eagle medium (Invitrogen). The medium was replaced every 3-4 days for 21 days. ${ }^{15-18}$

\section{Histology}

The cultures were ended by fixing the pellets with $2.5 \%$ glutaraldehyde in $0.1 \mathrm{M}$ PBS for $2 \mathrm{~h}$. The cells were washed overnight at $4{ }^{\circ} \mathrm{C}$ in the same buffer and post-fixed with $1 \%$ $\mathrm{OsO} 4$ buffered with $0.1 \mathrm{M}$ PBS for $2 \mathrm{~h}$. The pellets were dehydrated in a graded series of ethanol and embedded in Epon 812. Semi-thin $(1 \mu \mathrm{m})$ sections for light microscopy were collected on glass slides and stained for $30 \mathrm{~s}$ with toluidine blue. $^{19}$

\section{Transmission Electron Microscopy}

Ultrathin $(90 \mathrm{~nm})$ sections were collected on copper grids, double-stained with uranyl acetate and lead citrate, and then examined by transmission electron microscopy (H-7100, Hitachi, Hitachinaka, Japan). ${ }^{19}$

\section{Immunohistochemistry}

The micromasses were fixed in $4 \%$ paraformaldehyde, dehydrated, and embedded in paraffin. Sections were cut at a thickness of $5 \mu \mathrm{m}$ and deparaffinized in xylene, dehydrated through graded alcohol, and pretreated with $0.4 \mathrm{mg} / \mathrm{ml}$ proteinase K (DAKO, Carpinteria, CA, USA) in Tris- $\mathrm{HCl}$ for $15 \mathrm{~min}$ for optimal antigen retrieval. Residual enzymatic activity was removed by washing in PBS, and nonspecific staining was blocked with PBS containing $10 \%$ normal horse serum for $20 \mathrm{~min}$. Mouse monoclonal antibodies against human type I and type II collagen (Daiichi Fine Chemical, Toyama, Japan; 1:100 dilution with PBS containing 1\% BSA) were applied for $1 \mathrm{~h}$. After extensive washing with PBS, a secondary antibody of biotinylated horse anti-mouse (1:200; 
Vector Laboratories, MA, USA) was applied for $30 \mathrm{~min}$. Immunostaining was detected by Vectastain $\mathrm{ABC}$ reagent (Vector Laboratories, Burlingame, CA, USA), followed by diaminobenzidine staining. ${ }^{19}$

\section{TUNEL and Ki67 Staining}

Immediately after fixation in $4 \%$ paraformaldehyde in $0.1 \mathrm{M}$ PBS for $1 \mathrm{~h}$, the micromasses were immersed in $1.8 \mathrm{M}$ sucrose containing $20 \%$ polyvinylpyrrolidone in $0.1 \mathrm{M}$ PBS for $24 \mathrm{~h}$ at $4{ }^{\circ} \mathrm{C}$, mounted on a holder, and quickly frozen in liquid nitrogen. Frozen sections were cut on an ultracut $\mathrm{S}$ microtome (Reichert, Wien, Austria) equipped with a low-temperature sectioning system (Reichert) at a thickness of $1 \mu \mathrm{m}$ at $-80^{\circ} \mathrm{C}$.

For TUNEL staining, an apoptosis in situ detection kit (Wako Pure Chemical Industries, Ltd, Osaka, Japan) was used. The frozen semi-thin sections were incubated with terminal deoxynucleotidyl transferase for $10 \mathrm{~min}$ at $37^{\circ} \mathrm{C}$ in a moist chamber. The sections were washed with $0.1 \mathrm{M}$ PBS for $15 \mathrm{~min}$. Peroxidase-conjugated antibody was then applied to the specimens at $37^{\circ} \mathrm{C}$ for $10 \mathrm{~min}$ in a moist chamber. The sections were developed with 3,3-diaminobenizidine, and counterstained with methyl green.

For Ki67 staining, the frozen semi-thin sections were blocked with $1 \%$ BSA in $0.1 \mathrm{M}$ PBS for $1 \mathrm{~h}$ at $4^{\circ} \mathrm{C}$. Mouse monoclonal anti-Ki67 antibody (Zymed, South San Francisco, CA, USA; 1:100 dilution with PBS containing 1\% BSA) was then incubated with the sections for $24 \mathrm{~h}$ at $4^{\circ} \mathrm{C}$. After extensive washing with $0.1 \mathrm{M}$ PBS, the sections were incubated for $10 \mathrm{~min}$ with biotinylated secondary antibodies. Immunostaining was detected with a Zymed Histostain kit (Zymed). Counterstaining was performed with methyl green.

\section{Immunocryo-ultramicrotomy}

The frozen ultrathin $(90 \mathrm{~nm})$ sections were collected on formvar-coated nickel grids and then placed on droplets of $1 \%$ BSA in $0.1 \mathrm{M}$ PBS. The sections were subsequently transferred to droplets of mouse antibody against collagen type I, II, X (Cosmo Bio, Japan), and chondroitin sulfate proteoglycan (Seikagaku Kogyo, Japan) for $12 \mathrm{~h}$ at $4^{\circ} \mathrm{C}$. The dilution of antibody against collagen type I, II, X, and chondroitin sulfate proteoglycan was 1:20, 1:20, 1:20, and 1:50 with 1\% BSA in 0.1 M PBS, respectively. Each section was then washed with $0.1 \mathrm{M}$ PBS and incubated with goat anti-rabbit IgG or goat anti-mouse IgG + IgM conjugated with $10 \mathrm{~nm} \Phi$ gold colloidal particles (diluted 1:20, $1: 20,1: 20$, and $1: 50$ with $1 \%$ BSA in $0.1 \mathrm{M}$ PBS, respectively; British Bio Cell International, UK) for $12 \mathrm{~h}$ at $4^{\circ} \mathrm{C}$. The sections were stained with $1 \%$ uranyl acetate, washed with distilled water, and then embedded with a mixture of $3 \%$ polyvinylalchol and $0.3 \%$ uranyl acetate. The sections were examined by transmission electron microscopy (H-7100, Hitachi). ${ }^{19}$

\section{RESULTS \\ Characterization of Bone Marrow-, Synovium-MSCs, and Chondrocytes}

We first analyzed the colony-forming capacity. When nucleated cells were plated at the same density, the number of developed colonies was highest in synovium-MSCs, was second highest in chondrocytes, and was the least highest in bone marrow-MSCs (Figure 1). To prepare colony-forming cells unaffected by colony-to-colony contact inhibition, we harvested bone marrow-MSCs plated at $10^{6} /$ dish, synoviumMSCs plated at $10^{4} / \mathrm{dish}$, and chondrocytes plated at $10^{5} / \mathrm{dish}$ for further analyses.

Flow cytometric analysis showed that each population of cells was negative for CD45 and positive for CD44, CD90, and CD105 (Figure 2). Bone marrow- and synovium-MSCs were calcified when cultured in medium containing $\beta$-glycerophosphate $^{20}$ and differentiated into adipocytes when cultured in medium containing isobutylmethylxanthine (data not shown). ${ }^{21}$

\section{In Vitro Chondrogenesis}

MSCs were pelleted into micromasses and then cultured in chondrogenic medium. Immediately after centrifugation, they appeared to be fragile and flat at the bottom of the tube (data not shown). One day later, they became substantial masses (Figure 3a). At day 7 and thereafter, they became round or elongated spheres, and their size and weight increased along with the culture period in the three populations (Figure $3 b$ ).

\section{Morphology of Cells Before Chondrogenic Induction}

Microscopically, the cells were dissociated and round in the three populations (Figure 4a). Transmission electron microscopy demonstrated a large number of elongated thin processes at the cell surface. The cells contained well-developed cell organelles, including mitochondria, endoplasmic reticulum, Golgi apparatus, lysosomes, and large quantities of free ribosomes. Their nuclei were euchromatic and notched (Figure $4 \mathrm{~b}$ ). The bone marrow-, synovium-MSCs, and chondrocytes looked similar before chondrogenic induction.

\section{Aggregation}

One day later, the cells aggregated into a firm pellet. Histological sections embedded in Epon showed that the structure of the three masses was divided into two layers: the superficial zone and the deep zone (Figure 5a). The superficial zone consisted of spindle cells parallel to the surface. In the deep zone, obvious morphological differences were observed in the three populations. In bone marrow-MSCs, pale-stained round cells accumulated without intercellular space. In the synovium-MSCs, the deep zone consisted of elongated cells, and intercellular spaces could occasionally be seen. In chondrocytes, oval and polygonal cells with abundant intercellular spaces comprised the deep zone. At this stage, type I 


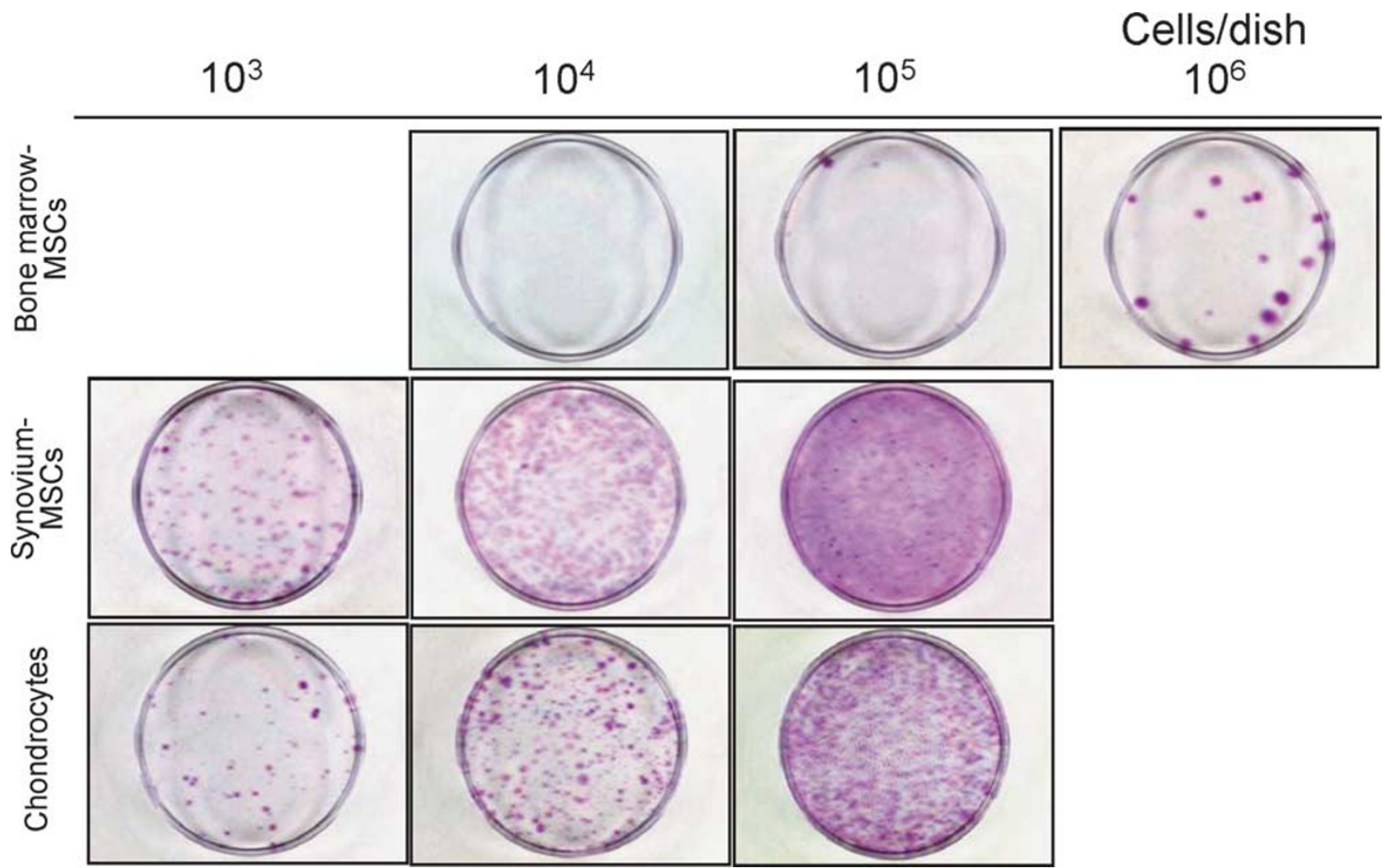

Figure 1 Colony formation of bone marrow-, synovium-MSCs, and chondrocytes. Nucleated cells were plated at indicated cell number per $60-\mathrm{cm}^{2}$ dish and cultured for 14 days. Culture dishes were stained with crystal violet.

collagen was detected in the intercellular spaces, whereas type II collagen was absent in the three populations (Figure 5b).

Morphological differences in the deep zone were analyzed by transmission electron microscopy (Figure 5c). In bone marrow-MSCs, round clear cells were attached to each other in a wide area. Cell-cell junctions mainly consisted of intermediate junctions (arrow heads), and desmosome (arrow) also existed. Extracellular matrix could not be seen. In synovium-MSCs, a small desmosome (arrow) was observed between oval cells. The contact area between each cell was smaller than that in bone marrow-MSCs. Collagen fibers (asterisk) existed in extracellular space. In chondrocytes, spindled cells appeared to be separated from each other or connected only in a narrow spotty area through a small desmosome (arrow). Extracellular space was larger than that in others. Collagen fibers (asterisk) could be seen.

\section{Early Phase of Differentiation}

At day 7 , the structure of the three masses appeared to be divided into three layers: the superficial zone, the middle zone, and the deep zone (Figure 6a). The superficial zone consisted of spindle-shaped cells organized along the surface of the pellet. The deep zone was composed of unorganized polygonal cells with intercellular space, which was narrow in synovium-MSCs, large in chondrocytes, and intermediate in bone marrow-MSCs. The middle zone could be distinguished between the superficial and the deep zone. In bone marrowMSCs, the middle zone consisted of smaller cells, and cell density was higher than in other zones. In synovium-MSCs, the middle zone appeared to be more obscure, but it consisted of more arrayed wider cells than superficial cells. In chondrocytes, the middle zone appeared to be almost acellular. Immunostaining demonstrated that bone marrow- and synovium-MSCs expressed type I collagen in the periphery. The three populations of MSCs expressed type II collagen diffusely (Figure 6b). TUNEL positive cells (Figure $6 \mathrm{c}$ ) and apoptotic cell death (Figure 6d) were observed sporadically in the middle zone of bone marrow- and synovium-MSCs, but could hardly be seen in chondrocytes. Ki67 expressions were also examined for proliferation but not observed in bone marrow- and synovium-MSCs (Figure 6e), and chondrocytes (data not shown).

\section{Late Phase of Differentiation}

At day 21, the intercellular spaces and their metachromasia became more prominent in the deep zone (Figure 7a). The superficial zone was still obvious in bone marrow-MSCs, but hardly seen both in synovium-MSCs and chondrocytes. The three populations increased both type I and type II collagen expression (Figure $7 \mathrm{~b}$ ). Mature chondrocyte-like cells were 

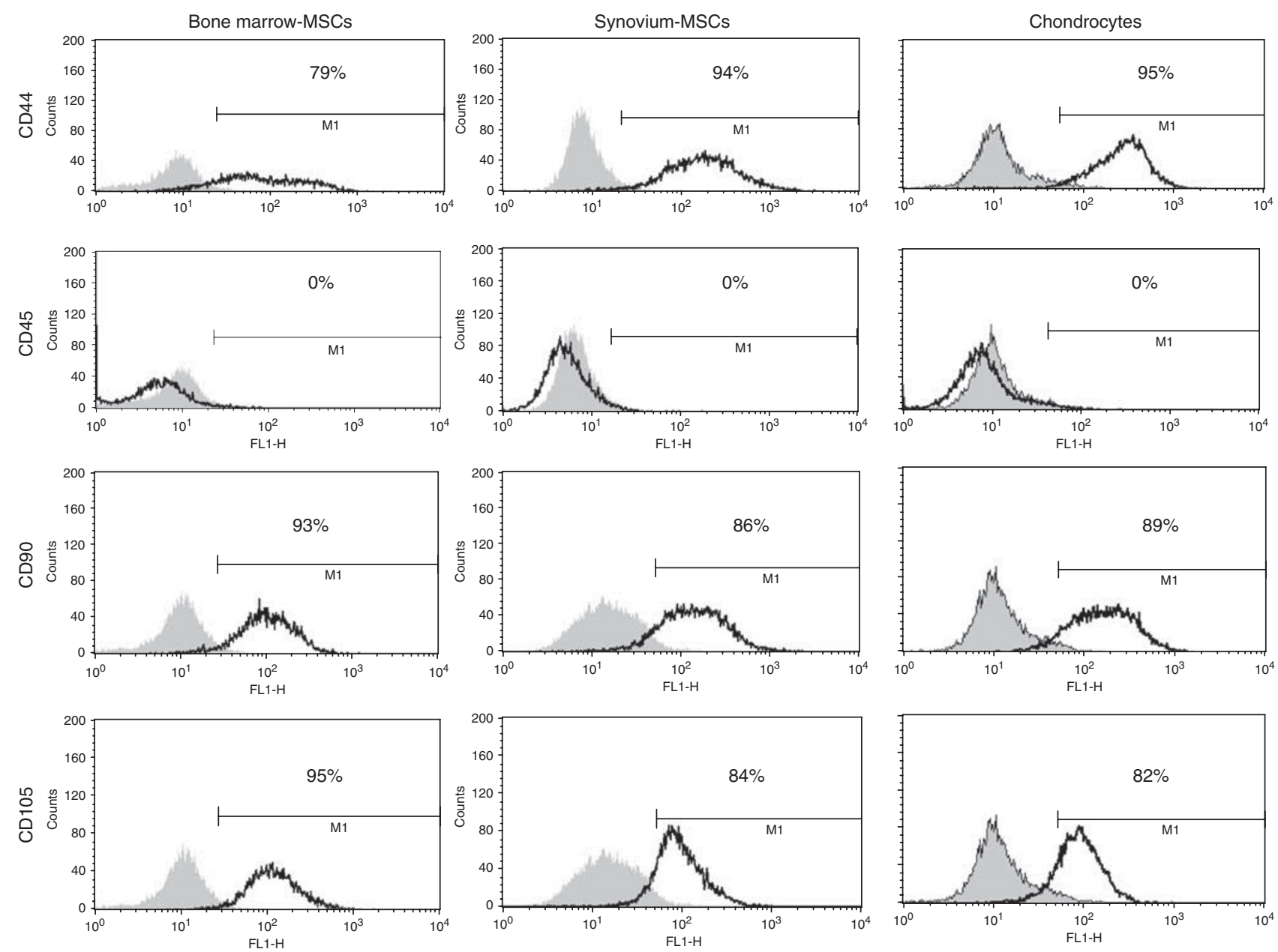

Figure 2 Surface epitopes of bone marrow-, synovium-MSCs, and chondrocytes. Representative histograms are shown as an open plot, and isotype controls are shown as gray.

a Bone marrow-MSCs
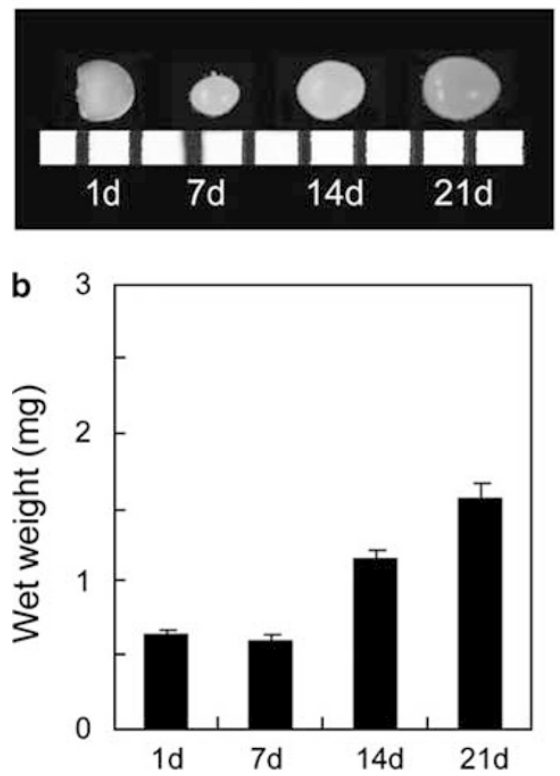

Synovium-MSCs
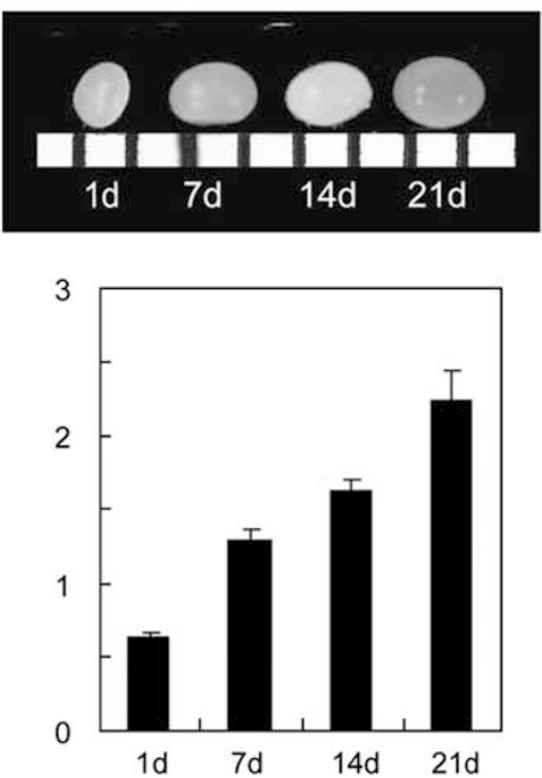

Chondrocytes
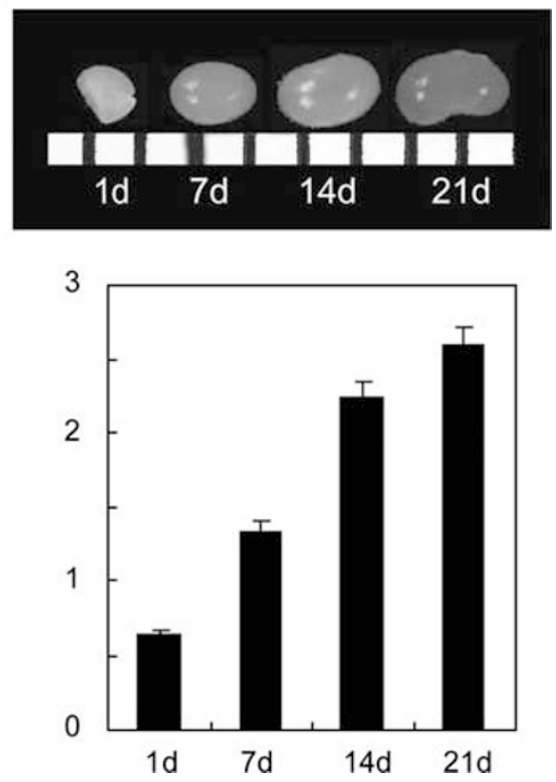

Figure 3 Time course of in vitro chondrogenesis of bone marrow-, synovium-MSCs, and chondrocytes. (a) Macro pictures of pellets with a 1-mm scale. (b) Wet weight of pellets. The data are expressed as mean \pm s.d. $(n=3)$. 
a

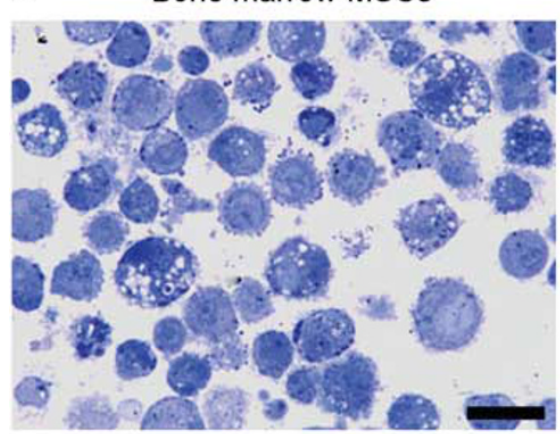

b

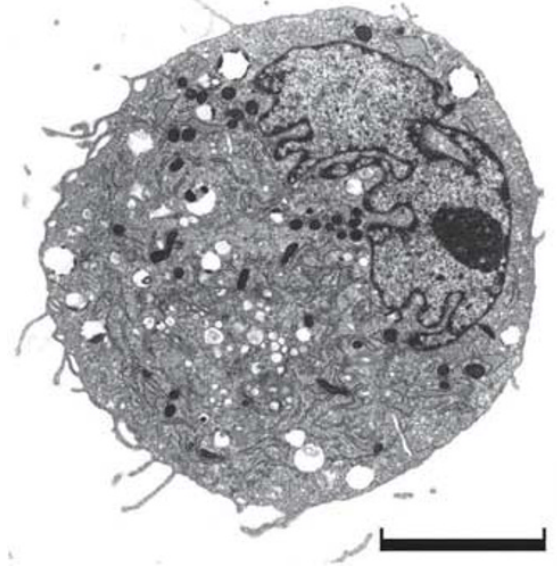

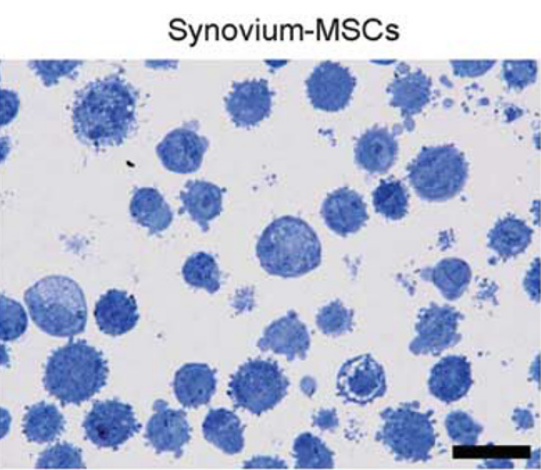
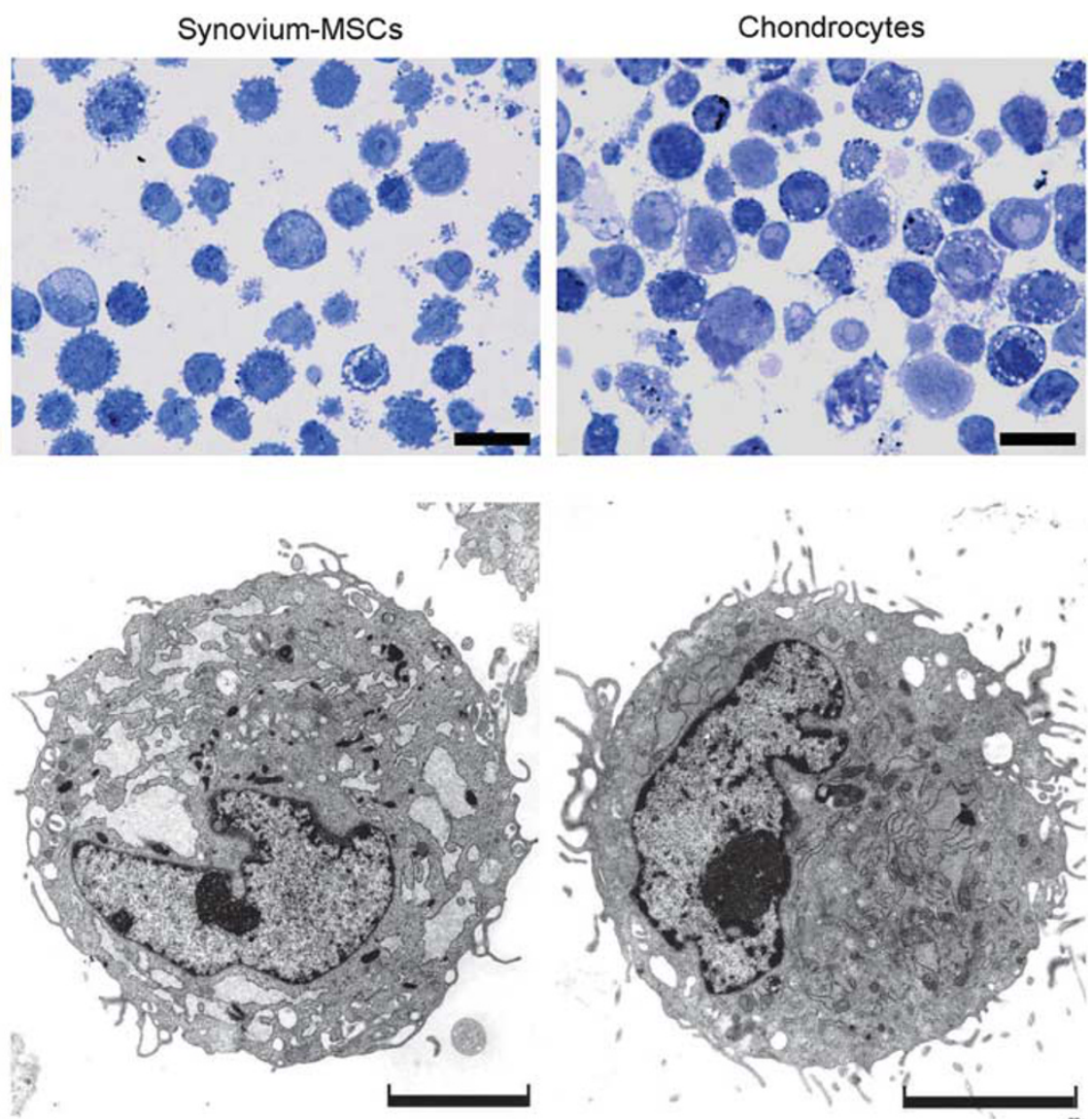

Figure 4 Morphology of bone marrow-, synovium-MSCs, and chondrocytes before induction of chondrogenesis. (a) Optical micrographs of the cells stained with toluidine blue. Scale bar $=20 \mu \mathrm{m}$. (b) TEM images. Scale bar $=5 \mu \mathrm{m}$.

observed by transmission electron microscopy images in the deep zone in the three populations. The cells with irregular contours were surrounded by well-developed matrix fibers (Figure 7c). Neither TUNEL positive nor Ki67 positive cells were observed. Immunoelectron microscopy at day 21 demonstrated only slight expression of type I collagen, and higher expression of type II, X collagen, and chondroitin sulfate in the deep zone in the three populations (Figure 8).

\section{DISCUSSION}

In this study, we compared the morphology of bone marrowMSCs, synovium-MSCs, and chondrocytes during their in vitro chondrogenesis (Table 1; Figure 9). Before induction for chondrogenesis, trypsinized cells looked similar among the three populations.

At day 1 (aggregation phase), the structure of the three masses was divided into two layers, and the most obvious differences in the three populations were observed at the deep zone. In bone marrow-MSCs, round cells accumulated without intercellular space, and the cells were mainly connected through intermediate junctions. In synoviumMSCs, elongated cells accumulated with small desmosomes, and intercellular spaces could occasionally be seen. In chondrocytes, separated oval and polygonal cells were connected only in a narrow spotty area through a small desmosome.

At day 7 (early phase of differentiation), the structure of the three masses was divided into three layers, and the most obvious differences in the three populations were observed at the middle zone. In bone marrow-MSCs, the middle zone consisted of dense smaller cells and apoptotic cells. In synovium-MSCs, the middle zone consisted of dense arrayed wider cells and apoptotic cells. In chondrocytes, the middle zone was acellular without apoptotic cells.

At day 21 (late phase of differentiation), the morphology of cells and extracellular space became similar in that each cell was located separately with abundant extracellular matrix. The superficial zone was still obvious in bone marrow-MSCs, but hardly seen both in synovium-MSCs and chondrocytes.

At the early phase, apoptotic cells were observed in the middle zone. The gradient of oxygen, cytokines, or other nutrients presumably affects the fate of the cells, ${ }^{19}$ and the middle zone might be an inappropriate environment for the cells located there. If this is the case, why were there no apoptotic cells of chondrocytes in the middle zone? One 
a

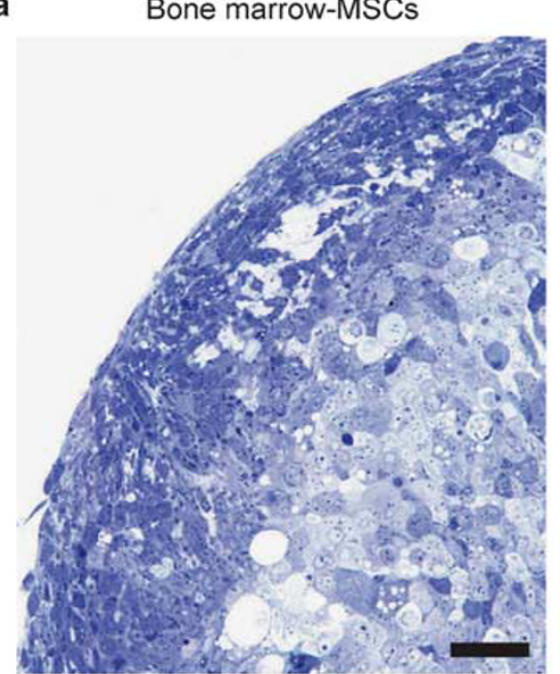

b
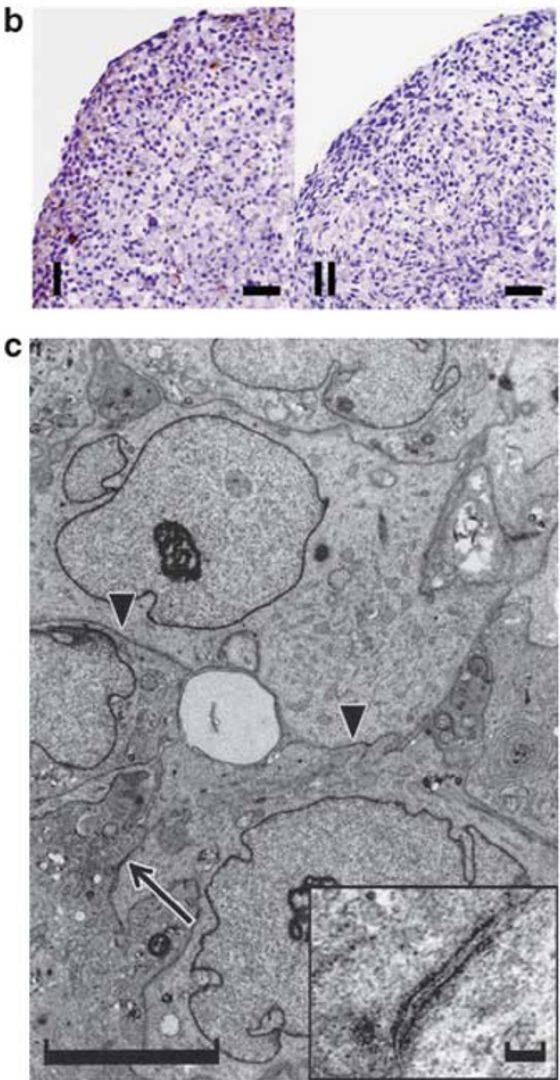

Synovium-MSCs
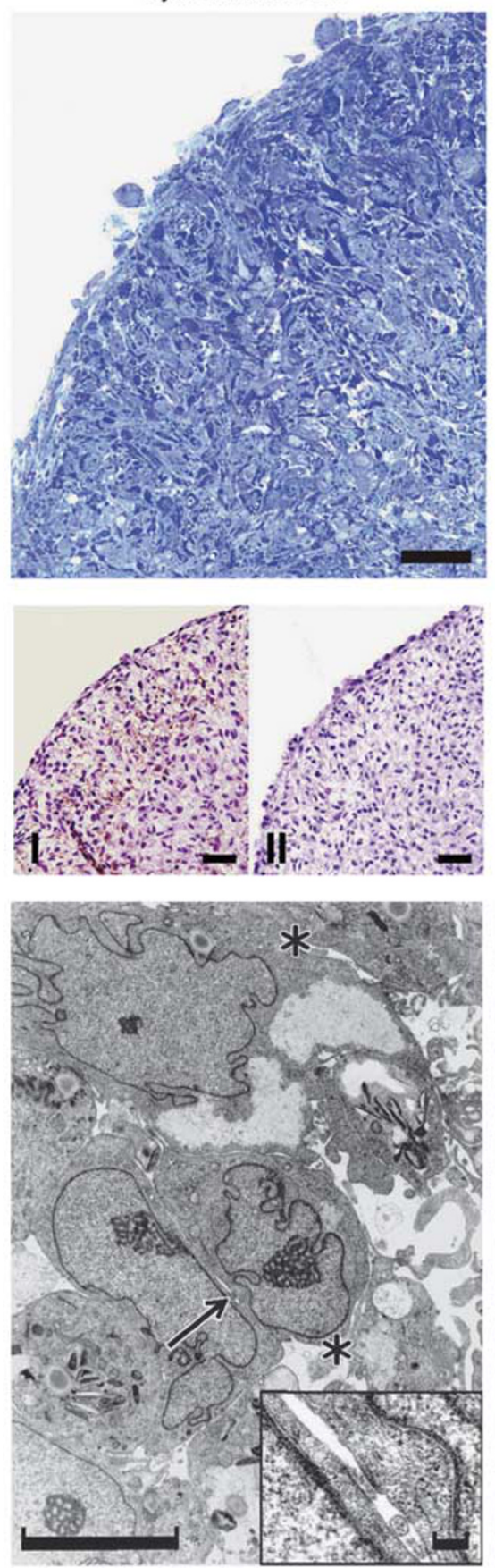

Chondrocytes
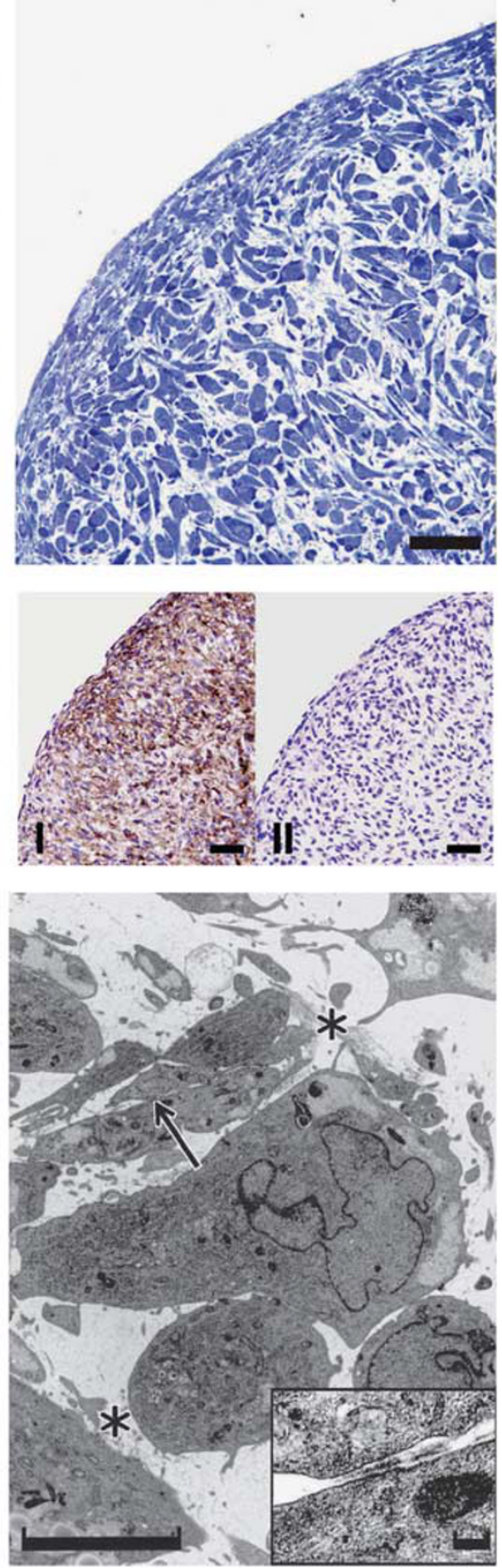

Figure 5 Morphology of pellets 1 day after induction of in vitro chondrogenesis. (a) Optical micrographs of pellets stained with toluidine blue. Scale $\mathrm{bar}=50 \mu \mathrm{m}$. (b) Immunohistochemical staining for type I and II collagen. Scale bar $=50 \mu \mathrm{m}$. (c) TEM images of pellets in the deep zone. Scale bar $=5 \mu \mathrm{m}$. In bone marrow-MSCs, intermediate junctions are shown as arrow heads, and desmosome as arrow. In synovium-MSCs and chondrocytes, small desmosomes are shown as arrow and type I collagen fibers as asterisks. Desmosome and small desmosomes are magnified. Scale bar $=100 \mathrm{~nm}$.

possibility is that chondrocytes do not die due to apoptosis during in vitro chondrogenesis. Tallheden et al ${ }^{22}$ reported that chondrocytes did not express apoptosis-related genes during in vitro chondrognesis.

In bone marrow- and synovium-MSCs, we observed TUNEL positive cells at day 7 and no TUNEL positive cells at day 21. In our earlier reports, DNA content decreased largely within the first week and only slightly between 2 and 3 weeks during in vitro chondrogenesis of MSCs derived from bone marrow $^{17}$ and synovium. ${ }^{23}$ The results of TUNEL assay in this study and the results of DNA content assays in earlier reports indicate one possibility that viable cells decreased 

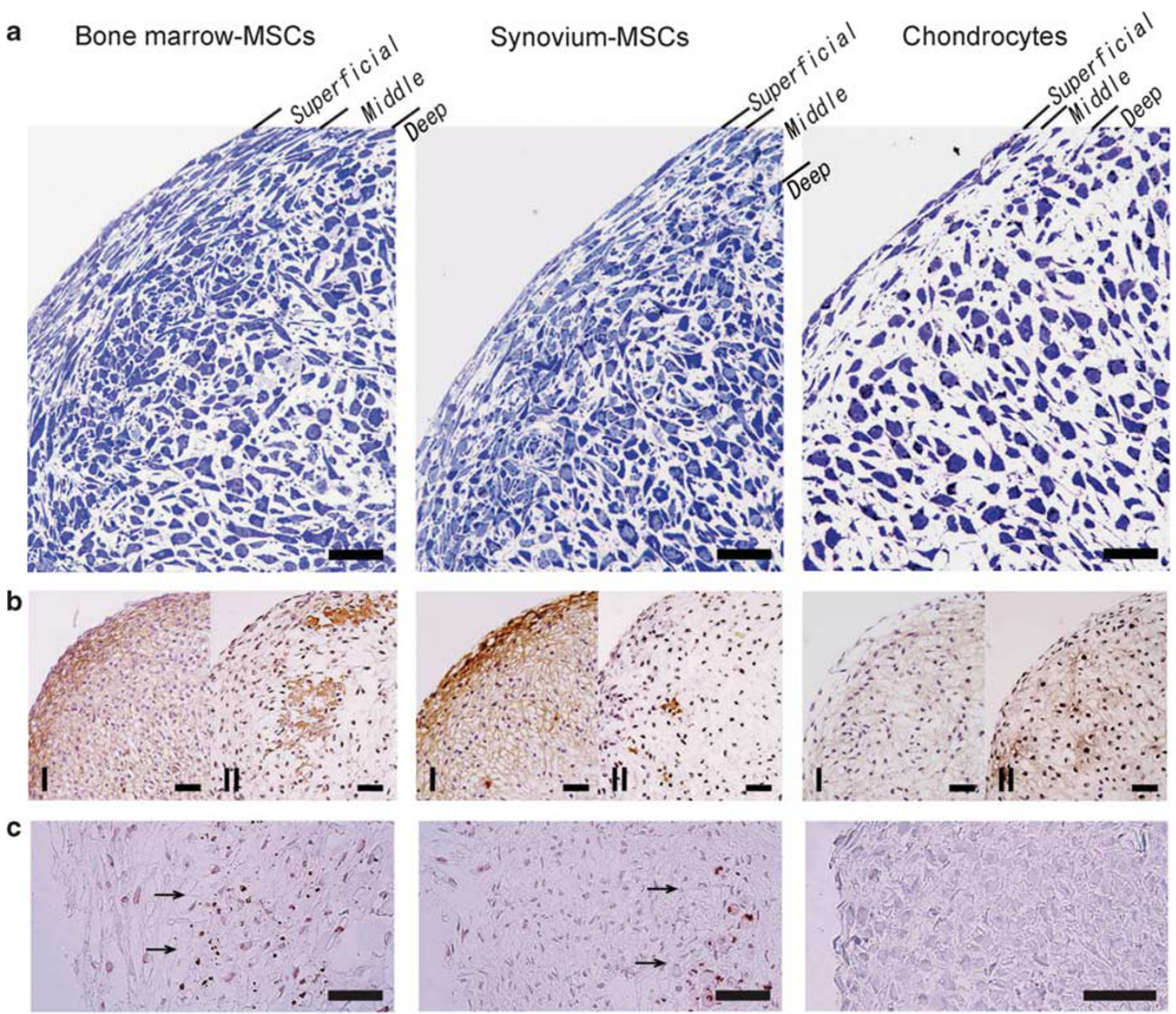

d
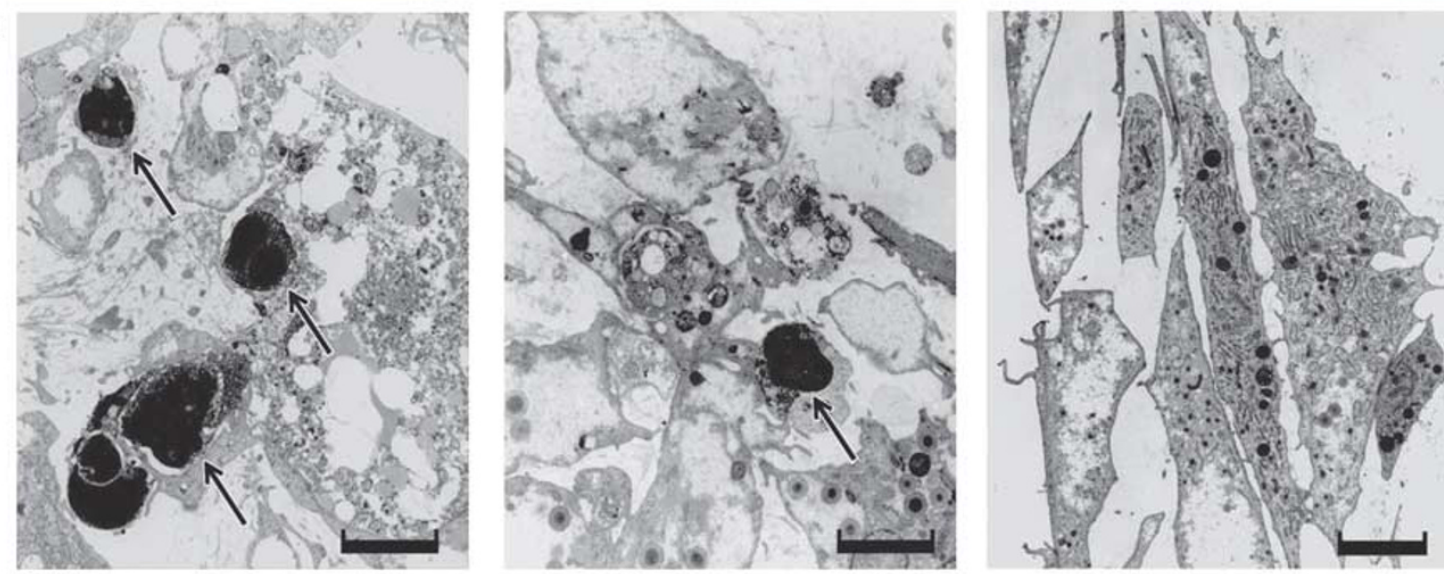

e
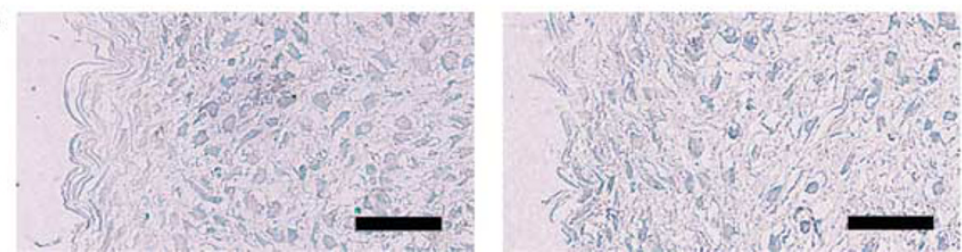

Positive control

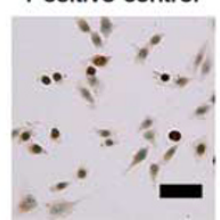

Figure 6 Morphology of pellets 7 days after induction of in vitro chondrogenesis. (a) Optical micrographs of pellets stained with toluidine blue. Scale bar $=50 \mu \mathrm{m}$. (b) Immunohistochemical staining for type I and II collagen. Scale bar $=50 \mu \mathrm{m}$. (c) TUNEL staining for apoptosis in the superficial and middle zone. TUNEL positive cells are shown as arrows. Scale bar $=50 \mu \mathrm{m}$. (d) TEM images in the middle zone. Apoptotic cells are shown as arrow. Scale bar $=5 \mu \mathrm{m}$. (e) Ki67 staining for proliferation in the superficial and middle zone. Hela cells are also shown as positive control. Scale bar $=50 \mu \mathrm{m}$. 
a

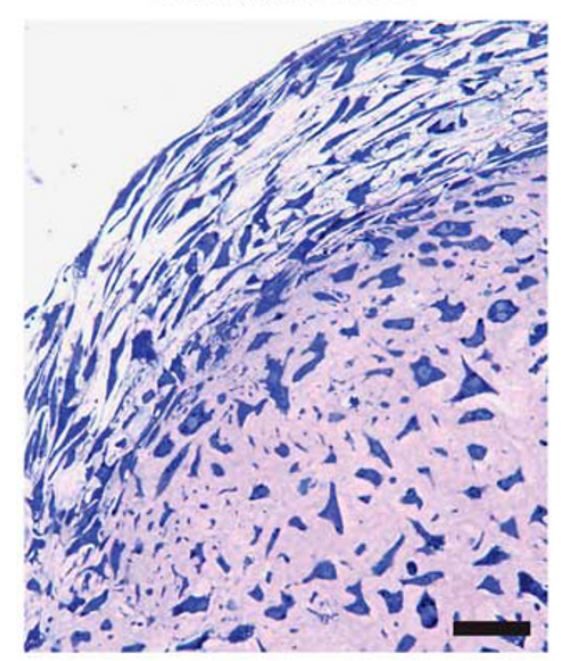

b

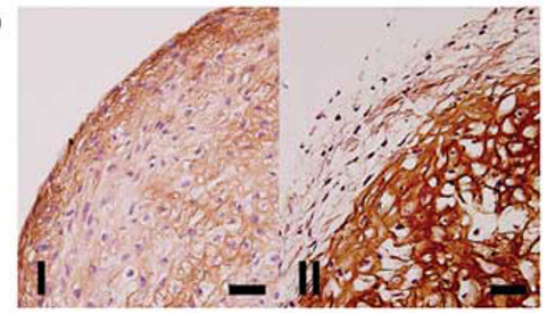

C

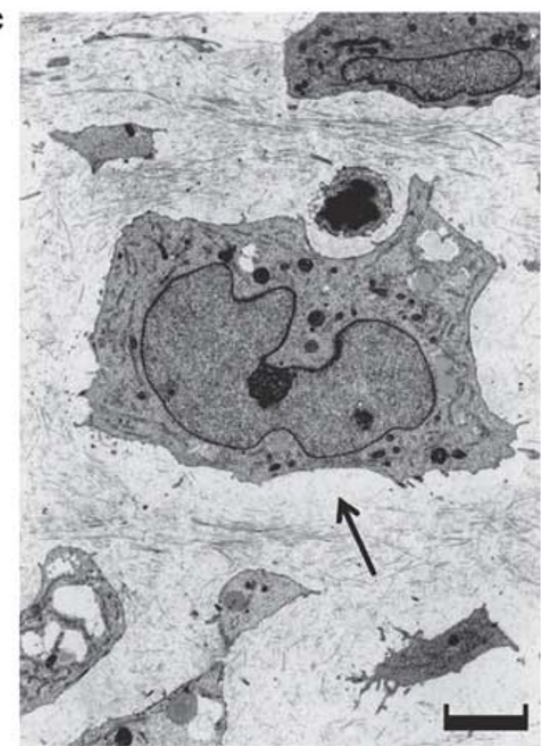

Synovium-MSCs

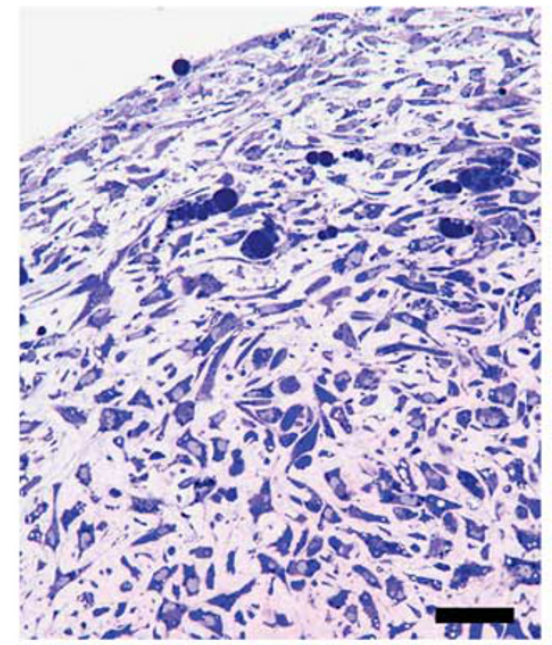

Chondrocytes

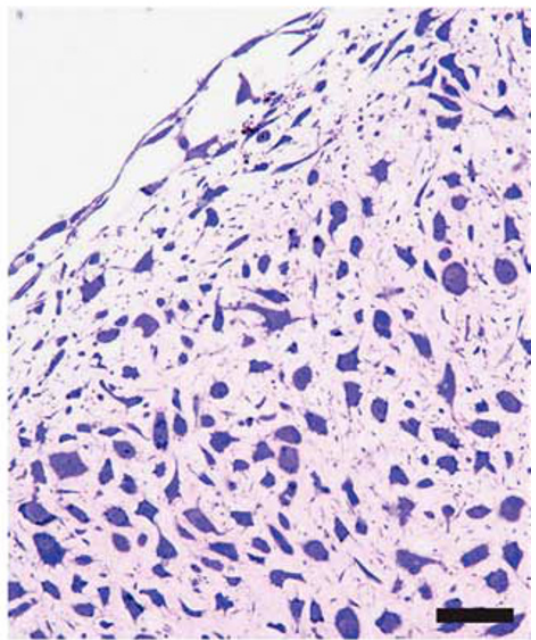

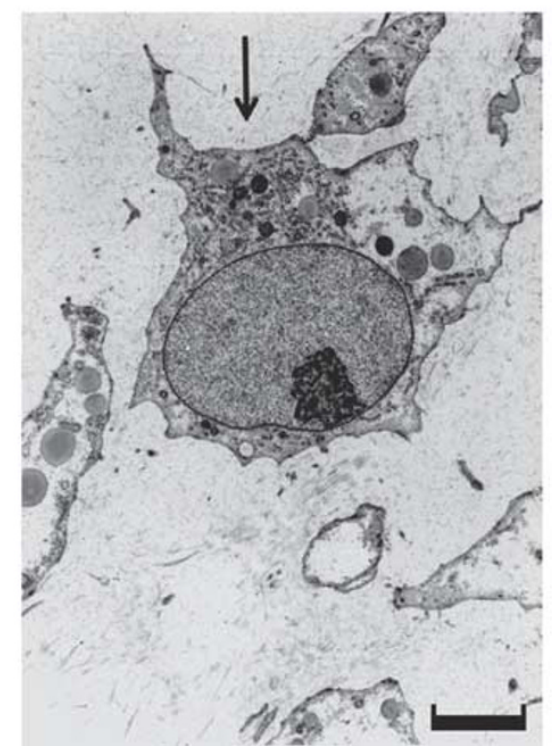

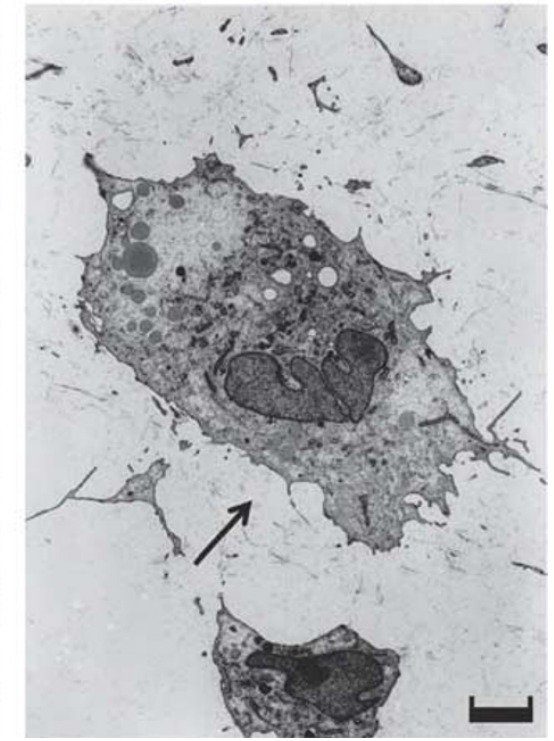

Figure 7 Morphology of pellets 21 days after induction of in vitro chondrogenesis. (a) Optical micrographs of pellets stained with toluidine blue. Scale bar $=50 \mu \mathrm{m}$. (b) Immunohistochemical staining for type I and II collagen. Scale bar $=50 \mu \mathrm{m}$. (c) TEM images in the deep zone. Mature chondrocyte-like cells are located at the center. Well-developed matrix fibers are shown as arrow. Scale bar $=5 \mu \mathrm{m}$.

largely within the first week and only slightly between 2 and 3 weeks because of apoptosis.

At the early phase of differentiation, pellets of bone marrow- and synovium-MSCs showed higher density of cells in the middle zone and demonstrated different features from that of chondrocytes. Was there any difference in cell proliferation between the cells? The answer is no. We examined Ki67 expressions for proliferation but did not observe any Ki67 expressions in the three populations. This indicates that different features between two populations of MSCs and chondrocytes in the middle zone were not due to cell proliferation. In our earlier report of bone 

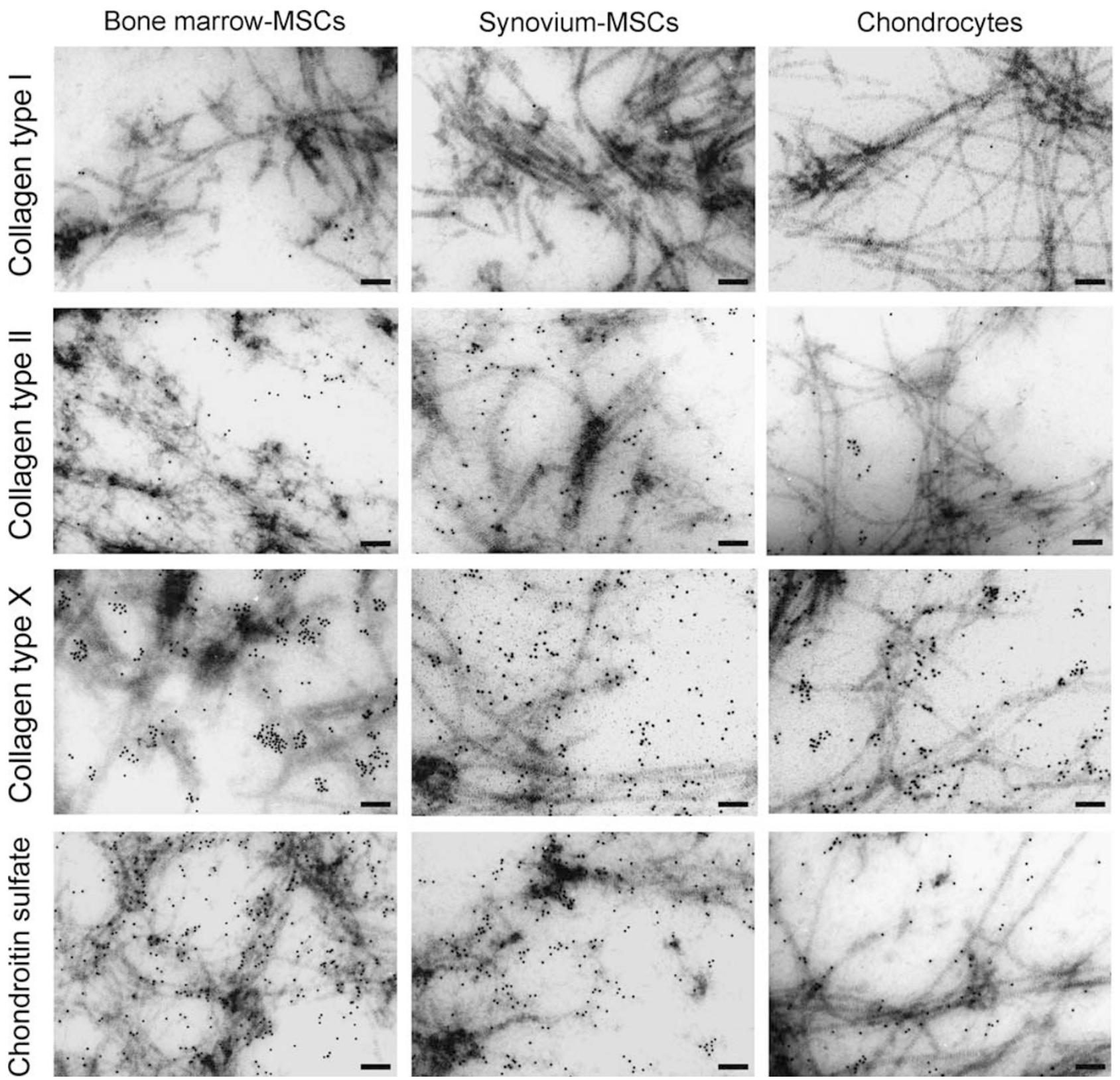

Figure 8 Immunoelectron microscopic images for pellets 21 days after induction of in vitro chondrogenesis. Expressions of collagen type I, II, X, and chondroitin sulfate proteoglycan in the deep zone by the gold particle deposition are shown. Scale bar $=100 \mathrm{~nm}$.

marrow-MSCs, a pulse-labeled and chase experiment with $\left[{ }^{3} \mathrm{H}\right]$ thymidine indicated that there was a $25 \%$ decrease in the specific activity of cellular DNA between day 0 and day 7 , but thereafter the values remained constant, ${ }^{17}$ demonstrating that bone marrow-MSCs did not divide at the early phase.

We performed all experiments in three donors with osteoarthritis, and similar results were obtained. To account for variances among donors and among procedures, ${ }^{5}$ we harvested bone marrow, synovium, and cartilage simultaneously after total knee arthroplasty, performed the procedures, and analyzed the cells from bone marrow, synovium, and carti- lage at the same time. It would be intriguing to examine whether similar results could be obtained in cells derived from young donors; however, it is not easy to harvest bone marrow, synovium, and especially cartilage from young donors simultaneously. The confirmation in young donors would be practically difficult.

Ectopic cartilage formation is one of the pathological conditions in articular joints. ${ }^{14}$ Candidate cell sources for the ectopic cartilage formations are stem cells in bone marrow and synovium, in addition to chondrocytes. A comparison of the morphology of cartilage formation between in vitro chondrogenesis of these cells and the ectopic cartilage for- 
Table 1 Critical differences of morphologies during in vitro chondrogenesis

\begin{tabular}{|c|c|c|c|c|}
\hline Days & Zone & Bone marrow-MSCs & Synovium-MSCs & Chondrocytes \\
\hline 0 & & \multicolumn{3}{|c|}{ Round cells with a large number of processes at the cell surface } \\
\hline 1 & Deep zone & Round cells without intercellular space & $\begin{array}{l}\text { Elongated cells with intermediate } \\
\text { intercellular spaces }\end{array}$ & $\begin{array}{l}\text { Oval and polygonal cells } \\
\text { with intercellular spaces }\end{array}$ \\
\hline \multirow[t]{4}{*}{7} & Superficial zone & \multicolumn{3}{|c|}{ Spindle cells parallel to the surface } \\
\hline & Middle zone & Higher cell density & Higher cell density & Lower cell density \\
\hline & & Apoptotic cells & Apoptotic cells & No apoptotic cells \\
\hline & Deep zone & Intermediate intercellular space & Relatively narrow intercellular space & Large intercellular space \\
\hline
\end{tabular}

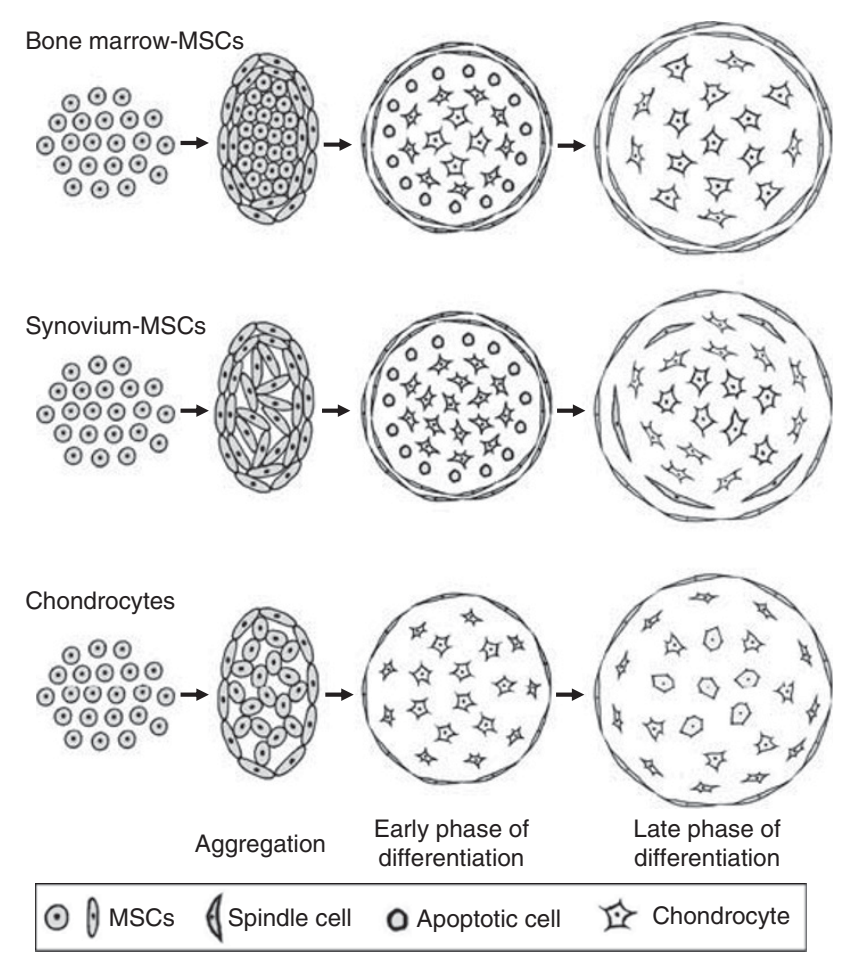

Figure 9 Scheme for morphological events during in vitro chondrogenesis of bone marrow-, synovium-MSCs, and chondrocytes. Explanations are summarized in Table 1.

mation could possibly clarify the cell source and the mechanisms of the ectopic cartilage formation.

The chondrogenic medium used in the study was previously demonstrated to be suitable for MSCs derived from bone marrow ${ }^{16,18}$ and synovium. ${ }^{23}$ This chondrogenic med- ium may not be optimal for chondrocytes. However, in this study, we demonstrated that colony-forming cells derived from cartilage produced cartilage matrix in the condition we used. If we had performed in vitro chondrogenesis of chondrocytes with a medium more suitable for chondrocytes, we could not have concluded that morphological differences are due to a different origin of the cells, because different culture medium may affect the morphology of the cells. Therefore, we used common chondrogenic medium for in vitro chondrogenesis of bone marrow-MSCs, synovium-MSCs, and chondrocytes.

There were some differences of histological patterns between toluidine blue and type II collagen staining, both of which were supposed to be correlated principally. We embedded histological samples in Epon for toluidine blue staining in order to enable detailed analysis, and in paraffin for immunohistology. ${ }^{19}$ We did not use serial sections for toluidine blue and type II collagen staining, resulting in different patterns between in toluidine blue and type II collagen staining.

For treatment of cartilage defect, transplantation of MSCs is an effective strategy. Among a variety of MSC sources, bone marrow and synovium are useful for high chondrogenic potential of their MSCs. The two MSCs contain common features, but distinguishing properties dependent on their origin are emerging. ${ }^{6-9,11,12}$ Colony-forming efficiency was higher in synovium-MSCs but colony size was larger in bone marrow-MSCs. ${ }^{7}$ Expression of PDGF receptor- $\alpha$ was higher in synovium-MSCs based on flow cytometrical analysis. ${ }^{12}$ In this study, we demonstrated morphological differences during in vitro chondrogenesis of bone marrow- and synoviumMSCs. Biologically, these differences are due to their different gene profiles. We previously compared gene profiles of bone 
marrow- and synovium-MSCs. The expression levels of chitinase 3-like 1 (CHI3L1), aggrecan 1, WINT1-inducible signaling pathway protein 2 (WISP2), fibulin 1, and S100 calcium-binding protein were extremely low in bone marrow-MSCs and high in synovium-MSCs. ${ }^{10}$

Cytologically, differences of cell-cell junctions at the aggregation phase in the three populations were interesting. Wuchter et al recently reported novel type cell junctions. They demonstrated that bone marrow-MSCs under monolayer conditions were interconnected by special tentacle-like cytoplasmatic protrusions and invaginations. ${ }^{24}$ Wagner and $\mathrm{Ho}^{25}$ described that the frequency and morphology of these conjunction complexes were greatly affected by culture conditions. In our experiments, further detailed investigation would provide new insight into the nature of cell junctions in MSCs during the chondrogenesis.

\section{Conclusions}

In this study, we revealed morphological differences of bone marrow-MSCs, synovium-MSCs, and chondrocytes during in vitro chondrogenesis. The most obvious differences in the three populations were observed at the aggregation phase in the deep zone.

\section{ACKNOWLEDGEMENTS}

We thank Kenjiro Wake for valuable suggestions, Akiko Yokoyama for in vitro chondrogenesis of MSCs, Miyoko Ojima for histological analyses, and Yuko Kawamura for preparing the figures. This study was supported by grants from the Japan Society for the Promotion of Science (19500403) to SI, (21591937) to TM, (21591914) to IS, and the Japanese Ministry of Education (Global Center of Excellence (GCOE)) Program, International Research Center for Molecular Science in Tooth and Bone Diseases, Tokyo Medical and Dental University to TM.

\section{DISCLOSURE/CONFLICT OF INTEREST}

The authors declare no conflict of interest.

1. Koga $\mathrm{H}$, Engebretsen $\mathrm{L}$, Brinchmann JE, et al. Mesenchymal stem cellbased therapy for cartilage repair: a review. Knee Surg Sports Traumatol Arthrosc 2009;17:1289-1297.

2. Koga $H$, Shimaya $M$, Muneta $T$, et al. Local adherent technique for transplanting mesenchymal stem cells as a potential treatment of cartilage defect. Arthritis Res Ther 2008;10:R84.

3. Koga $\mathrm{H}$, Muneta $\mathrm{T}$, Ju YJ, et al. Synovial stem cells are regionally specified according to local microenvironments after implantation for cartilage regeneration. Stem Cells 2007;25:689-696.

4. Horie M, Sekiya I, Muneta T, et al. Intra-articular injected synovial stem cells differentiate into meniscal cells directly and promote meniscal regeneration without mobilization to distant organs in rat massive meniscal defect. Stem Cells 2009;27:878-887.

5. Sekiya I, Larson BL, Smith JR, et al. Expansion of human adult stem cells from bone marrow stroma: conditions that maximize the yields of early progenitors and evaluate their quality. Stem Cells 2002;20:530-541.

6. Koga $H$, Muneta $T$, Nagase $T$, et al. Comparison of mesenchymal tissues-derived stem cells for in vivo chondrogenesis: suitable conditions for cell therapy of cartilage defects in rabbit. Cell Tissue Res 2008;333:207-215.
7. Sakaguchi Y, Sekiya I, Yagishita K, et al. Comparison of human stem cells derived from various mesenchymal tissues: superiority of synovium as a cell source. Arthritis Rheum 2005;52:2521-2529.

8. Yoshimura $\mathrm{H}$, Muneta $T$, Nimura $A$, et al. Comparison of rat mesenchymal stem cells derived from bone marrow, synovium, periosteum, adipose tissue, and muscle. Cell Tissue Res 2007;327: 449-462.

9. Mochizuki $T$, Muneta $T$, Sakaguchi $Y$, et al. Higher chondrogenic potential of fibrous synovium- and adipose synovium-derived cells compared with subcutaneous fat-derived cells: distinguishing properties of mesenchymal stem cells in humans. Arthritis Rheum 2006;54:843-853.

10. Morito T, Muneta T, Hara K, et al. Synovial fluid-derived mesenchymal stem cells increase after intra-articular ligament injury in humans. Rheumatology (Oxford) 2008;47:1137-1143.

11. Segawa $\mathrm{Y}$, Muneta $\mathrm{T}$, Makino $\mathrm{H}$, et al. Mesenchymal stem cells derived from synovium, meniscus, anterior cruciate ligament, and articular chondrocytes share similar gene expression profiles. J Orthop Res 2008;27:435-441.

12. Nimura $A$, Muneta $T$, Koga $H$, et al. Increased proliferation of human synovial mesenchymal stem cells with autologous human serum: comparisons with bone marrow mesenchymal stem cells and with fetal bovine serum. Arthritis Rheum 2008;58:501-510.

13. Saris DB, Vanlauwe J, Victor J, et al. Characterized chondrocyte implantation results in better structural repair when treating symptomatic cartilage defects of the knee in a randomized controlled trial versus microfracture. Am J Sports Med 2008;36: 235-246.

14. Kirsch T. Determinants of pathological mineralization. Curr Opin Rheumatol 2006;18:174-180.

15. Nagase T, Muneta T, Ju YJ, et al. Analysis of the chondrogenic potential of human synovial stem cells according to harvest site and culture parameters in knees with medial compartment osteoarthritis. Arthritis Rheum 2008;58:1389-1398.

16. Sekiya I, Colter DC, Prockop DJ. BMP-6 enhances chondrogenesis in a subpopulation of human marrow stromal cells. Biochem Biophys Res Commun 2001;284:411-418.

17. Sekiya I, Vuoristo JT, Larson $\mathrm{BL}$, et al. In vitro cartilage formation by human adult stem cells from bone marrow stroma defines the sequence of cellular and molecular events during chondrogenesis. Proc Natl Acad Sci USA 2002;99:4397-4402.

18. Sekiya I, Larson BL, Vuoristo JT, et al. Comparison of effect of BMP-2, -4, and -6 on in vitro cartilage formation of human adult stem cells from bone marrow stroma. Cell Tissue Res 2005;320:269-276.

19. Ichinose $S$, Tagami M, Muneta $T$, et al. Morphological examination during in vitro cartilage formation by human mesenchymal stem cells. Cell Tissue Res 2005;322:217-226.

20. Sakaguchi Y, Sekiya I, Yagishita K, et al. Suspended cells from trabecular bone by collagenase digestion become virtually identical to mesenchymal stem cells obtained from marrow aspirates. Blood 2004;104:2728-2735.

21. Sekiya I, Larson BL, Vuoristo JT, et al. Adipogenic differentiation of human adult stem cells from bone marrow stroma (MSCs). J Bone Miner Res 2004;19:256-264.

22. Tallheden T, Karlsson C, Brunner A, et al. Gene expression during redifferentiation of human articular chondrocytes. Osteoarthritis Cartilage 2004;12:525-535.

23. Shirasawa S, Sekiya I, Sakaguchi Y, et al. In vitro chondrogenesis of human synovium-derived mesenchymal stem cells: optimal condition and comparison with bone marrow-derived cells. J Cell Biochem 2006;97:84-97.

24. Wuchter P, Boda-Heggemann J, Straub BK, et al. Processus and recessus adhaerentes: giant adherens cell junction systems connect and attract human mesenchymal stem cells. Cell Tissue Res 2007;328:499-514.

25. Wagner $\mathrm{W}, \mathrm{Ho}$ AD. Mesenchymal stem cell preparations-comparing apples and oranges. Stem Cell Rev 2007;3:239-248. 